\title{
The spatial scaling of saprotrophic fungal beta diversity in decomposing leaves
}

\author{
LARRY M. FEINSTEIN ${ }^{1}$ and CHRISTOPHER B. BLACKWOOD \\ Department of Biological Sciences, Kent State University, 215 Cunningham Hall, Kent, OH 44242, USA
}

\begin{abstract}
Assembly of fungal communities remains poorly understood in part because of the daunting range of spatial scales that may be involved in this process. Here, we use individual leaves as a natural sampling unit, comprising spatially distinct habitat and/ or resource patches with unique histories and suites of resources. Spatial patterns in fungal beta diversity were tested for consistency with the metacommunity paradigms of species sorting and neutral dynamics. Thirty senesced leaves were collected from the forest floor ( $\mathrm{O}$ horizon) in replicate upland forest, riparian forest and vernal pool habitats. We quantified spatial distance between leaves, and fungal community composition was assayed by terminal restriction fragment length polymorphism. Significant distance-decay relationships were detected at all but one upland site. This is the first study where changes in fungal community composition were quantified across discrete adjacent habitat patches, providing evidence that fungal distance decay is operational at a scale of centimetres. Although leaves of differing lignin contents were sampled from each site, leaf type was not consistently important in explaining variation in fungal community composition. However, depth of a leaf within the forest floor significantly influenced community composition at five of six sites. Environmental heterogeneity associated with depth could include moisture gradients, relative influence of soil or spore colonization, and impact of forest floor biotic community (i.e. collembola and earthworms). Because the influence of spatial distance and depth on fungal community composition could not be disentangled, both species-sorting and neutral processes may be embedded within the distance-decay relationships that we found.
\end{abstract}

Keywords: distance decay, fungal community composition, leaf litter, neutral dynamics, species sorting, $\beta$-diversity

Received 2 August 2012; revision received 30 October 2012; accepted 1 November 2012

\section{Introduction}

A long-standing focus of community ecology has been to quantify and understand patterns of species diversity (Whittaker 1972; May 1976). Because community composition of macro-organisms is easier to characterize than that of micro-organisms, most work examining species diversity has been conducted on macro-organisms (Green \& Bohannan 2006; Nemergut et al. 2011). How-

Correspondence: Christopher B. Blackwood, Fax: 330672 3713; E-mail: cblackwo@kent.edu

${ }^{1}$ Present address: Department of Microbiology, University of Massachusetts 104 Morrill Science Center IVN University of Massachusetts Amherst 639 North Pleasant Street Amherst, MA 01003 email: feinsteinlm@gmail.com ever, saprotrophic fungi play a critical role in global carbon and nutrient cycling (Berg \& Laskowski 2006; Peay et al. 2008), and fungal diversity has been shown to impact ecosystem function (Tiunov \& Scheu 2005; Fukami et al. 2010). To understand the link between fungal diversity and ecosystem function under natural conditions, we must develop an understanding of how fungal diversity changes with spatial scale (Zak \& Visser 1996; Fierer et al. 2007). This would also make an important contribution to the investigation of whether diversity patterns are similar for micro-organisms and macro-organisms (Green \& Bohannan 2006).

Like most ecological guilds, saprotrophic fungi include species that interact with the environment at differing spatial scales. A particular fungus may be limited to spore dispersal or may have mycelia that can 
span multiple leaves and extend metres in diameter (Boddy et al. 2008). However, in either case, each senesced tree leaf is a natural environmental unit that has a distinct boundary, history and pool of resources (i.e. nutrients and carbon compounds). Thus, each senesced leaf can be considered a habitat patch, with resources often differing among tree species (Cornwell et al. 2008), that must be individually colonized by available fungi whose interactions result in the fungal community for the leaf. Leaves on the forest floor therefore form natural mixtures of overlapping habitat patches that can be treated as a spatial network. Using these natural habitat patches, spatial analyses can be used to examine distance-decay relationships, which define how diversity changes with spatial scale (Nekola \& White 1999), and test alternative theories about what processes drive beta diversity (Holt 2002; Brose et al. 2004; Filotas et al. 2010; Jabot \& Bascompte 2012).

There are two primary contrasting theories about controls over community beta diversity (the turnover of taxa among communities) (Leibold et al. 2004). Under species sorting, community composition is a response to a variety of environmental filters that exclude community members that cannot live within the niche space provided by the habitat patch (Whittaker 1972). Hence, differences in community structure driven by species sorting are correlated with gradients in the environment. In contrast, neutral theory states that all organisms have similar competitive capabilities and are not sorted by niches (Hubbell 2001). Under neutral theory, community composition is related to dispersal limitation, because colonization of a habitat patch is much more likely from taxa that are nearby the patch compared to taxa that are not. Thus, community composition would be primarily structured by spatial distance regardless of environmental conditions (Hubbell 2001).

Evidence has been found showing that fungal communities can be influenced by species sorting (Helgason et al. 2002; Öpik et al. 2009), neutral dynamics (Peay et al. 2010) or a combination of both processes (Lekberg et al. 2007; Dumbrell et al. 2010; Kivlin et al. 2011). These findings indicate that communities may be influenced by different ecological processes, depending on the habitat, community and spatial scale. However, it has previously been pointed out that environmental variability and spatial distance can be difficult to disentangle (Gilbert \& Lechowicz 2004), and most communities are probably influenced to some degree by both species-sorting and neutral processes (Gravel et al. 2006).

Our objective was to quantify fungal $\beta$-diversity on individual senesced forest leaves in several forest habitats to determine whether $\beta$-diversity patterns were consistent with patterns predicted by neutral dynamics, species sorting or both. Leaves known to differ in biochemical composition were harvested from three forest habitats (upland forest, riparian forest and vernal pool) that were selected to provide environmental variability. We collected leaves at each site in a manner that allowed us to quantify their spatial proximity ('leaf network topology'), which was then used to construct spatial distance matrices. Because of the commonness of the distance-decay pattern for micro-organisms (Green \& Bohannan 2006; Martiny et al. 2006; Astorga et al. 2012), we hypothesized that we would find similar distance-decay relationships within these small leaf neighbourhoods, where dispersal may not be expected to be limited. We also hypothesized that $\beta$-diversity would be highest within riparian forest because it experiences relatively high seasonal moisture fluctuations (i.e. flooding from the river and run-off from upland) and is a transition zone that may be colonized from both drier upland and saturated vernal pools. We used collector's curve analysis to determine whether community composition stabilizes after sampling a certain number of habitat patches (Gotelli \& Colwell 2001) and whether the stabilization is dependent on site $\beta$-diversity. Finally, we tested the relative influence of species-sorting and neutral processes within each site and across all sites. We predicted that leaf type and habitat type would serve as species-sorting filters, with evidence of dispersal limitation indicated by additional variation in community composition explained by spatial distance among communities. We used the molecular fingerprinting method such as terminal restriction fragment length polymorphism (TRFLP; Liu et al. 1997) to obtain a profile of fungal community composition. To assess the similarity in community relationships uncovered by TRFLP and the higher-resolution but lower-throughput method of sequence analysis, ordinations of TRFLP profiles and sequence data (described in Feinstein \& Blackwood 2012) were directly compared for a small group of samples.

\section{Methods}

\section{Leaf collection}

Leaves were harvested in June 2008 from duplicate $850-\mathrm{cm}^{2}$ plots located within three deciduous forest habitats (upland, riparian and vernal pool) in Jennings Woods, NE Ohio. The forest habitats were selected to provide abiotic and biotic variability (e.g. variation in moisture saturation). Thirty leaves were collected at each site. To have consistent variation in leaf resource pools across all sites, we collected at least 10 American beech (Fagus grandifolia) and 10 sugar maple (Acer saccharum) leaves at each site, if possible. The remaining leaves collected 
were comprised of whatever leaves were embedded in the habitat patch network at that site. To document the in situ layout of leaves collected, a tripod-mounted camera was used to record images of the plot before and after each leaf was removed. Individual leaves were collected with sterile implements, photographed, placed in preweighed containers and stored in the field on dry ice. Leaves were lyophilized at $-60{ }^{\circ} \mathrm{C}$ (VirTis Genesis 25EL; Biopharma Process Systems Ltd, Winchester, NH, USA), and dry leaf weight was recorded, followed by grinding in sterile collection vials in a Genogrinder 2000 (SPEX CertiPrep; Metuchen, NJ, USA).

\section{Fungal community composition}

After grinding, DNA was extracted from entire leaves without subsampling. DNA extraction was performed using $\mathrm{CTAB}$ extraction buffer and bead beating as described in $\mathrm{Wu}$ et al. (2011). PCR amplification of the ITS-1 region was performed using the primers NSI1F (5'-GATTGAATGGCTTAGTGAGG) and 5.8SR (5'-GCTGCGTTCTTCATCGA) (Martin \& Rygiewicz 2005). The forward primer was labelled with hexachloro6-carboxyfluorescein (HEX). PCRs were performed with a DNA Engine Dyad Peltier Thermal Cycler (Bio-Rad, Hercules, CA, USA) using $0.025 \mathrm{U} / \mu \mathrm{L}$ Taq DNA polymerase, $3 \mathrm{~mm} \mathrm{MgCl}_{2}, 1 \times$ ammonium polymerase buffer (B-Bridge International, Mountain View, CA, USA), $0.2 \mu \mathrm{M}$ each primer (Integrated DNA Technologies, Coralville, IA, USA), $0.16 \mathrm{~mm}$ each dNTP and $0.1 \mu \mathrm{g} / \mu \mathrm{L}$ bovine serum albumin (New England Biolabs, Ipswich, MA, USA). PCR conditions were as follows: initial denaturation for $3 \mathrm{~min}$ at $95^{\circ} \mathrm{C}, 30-35$ cycles of denaturation for $30 \mathrm{~s}$ at $94{ }^{\circ} \mathrm{C}$, primer annealing for $30 \mathrm{~s}$ at $60{ }^{\circ} \mathrm{C}$ and extension for $90 \mathrm{~s}$ at $72{ }^{\circ} \mathrm{C}$, and a final extension for $7 \mathrm{~min}$ at $72{ }^{\circ} \mathrm{C}$. Negative controls were included in each PCR run. PCR products were run on a $1.5 \%$ agarose gel to confirm successful amplification. Cycle number varied for each sample to obtain a strong band without non-specific amplification.

To generate TRFLP profiles, three replicate PCRs were performed for each sample, and these were pooled prior to restriction enzyme digestion. Samples were digested overnight at $37^{\circ} \mathrm{C}$ with 10 units HaeIII (New England Biolabs, Ipswich, MA, USA) and cleaned with a DNA probe purification kit (Zymo Research, Irvine, CA, USA). Digested PCR products were sent to the Ohio State Plant Microbe Genomics Facility for fragment analysis on an Applied Biosystems 3730 DNA Analyzer using a LIZ1200 size standard and minimum peak height of 50 fluorescence units. Peaks between 50 and $600 \mathrm{bp}$ were included in the analysis if they represented $\geq 0.5 \%$ relative peak height abundance for the sample.

\section{Construction of distance matrices from leaf habitat patch networks}

For each site, the series of field photographs taken before and after sampling each leaf was utilized to record the location of each leaf within the forest floor. Depth of each leaf within the network was recorded as a potential explanatory variable because of probable environmental heterogeneity at the top compared to the bottom of the forest floor. Images and leaf locations were used to visually estimate the percent surface area overlap between each pair of leaves $(0 \%, 20 \%, 40 \%$, $60 \%, 80 \%$ or $100 \%$ ), which was recorded in a proximity matrix. The proximity matrix was nonsymmetric, because overlapping leaves often differed in size. We considered leaves to be overlapping only if they physically touched each other in the field, not if they were in similar positions but in differing layers in the forest floor. Network topology was then generated from proximity matrices using the package RBGL (Long et al. 2011) in the software $R$ (Version 2.12.1) and Graphviz (Ellson et al. 2000). All leaves were connected (touching at least one other leaf) at three sites, but we collected one or more nonconnected leaves at three sites (Fig. 1). This was due to a lower abundance of beech and maple at some sites which necessitated a somewhat scattered leaf collection pattern to obtain at least 10 of each of those leaf types.

We excluded nonconnected leaves and calculated two types of 'spatial' leaf distance matrices for each site. For the first type of distance matrix, we calculated 'step distance' by finding the shortest number of steps between each pair of leaves (i.e. the distance between two adjacent or overlapping leaves was one step, the distance between two leaves with one other leaf between them was two steps, etc.). In the second distance matrix, we calculated a 'weighted distance' where each step was replaced by a distance value equal to $100 \%$ minus the percentage overlap that the step represented (i.e. percentage of area not overlapping). For overlapping leaves of differing sizes, we used the smaller percentage overlap value. The weighted distance between two nonoverlapping leaves (i.e. leaves separated by greater than one step) equalled the sum of the distance values for all steps in the shortest path between the leaves.

\section{Statistical analysis}

Analysis of environmental and spatial factors within sites. To determine the relative influence of species-sorting and neutral processes, we compared the influence of spatial vs. environmental variables on fungal community composition using both Mantel analysis and redundancy analysis (RDA; Legendre \& Legendre 1998). Beta 

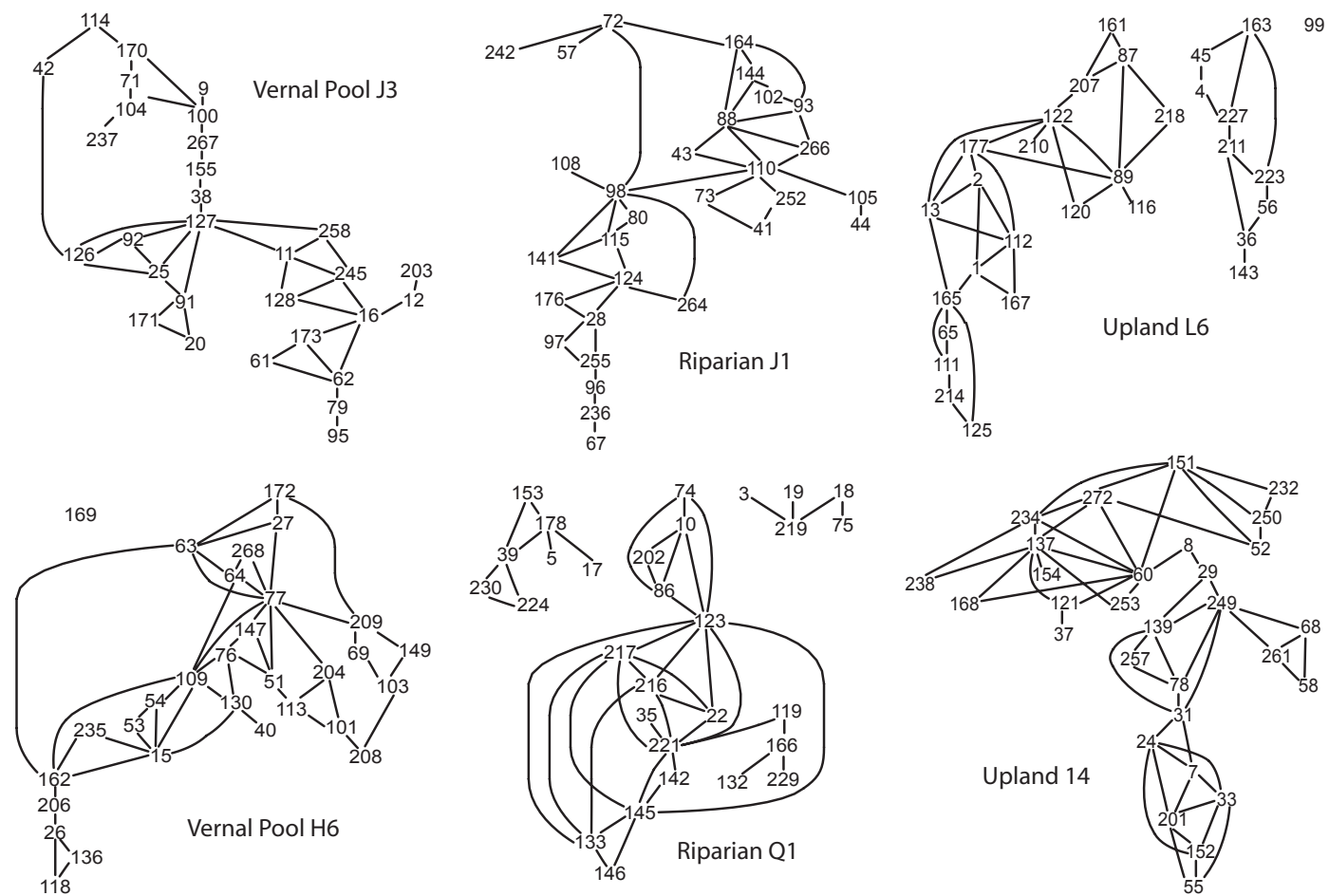

Fig. 1 Graphical representation of step-distance matrix showing connections between leaves collected at each Jennings Woods site.

diversity explained solely by spatial effects provides support for dispersal limitation and neutral processes. Beta diversity explained solely by leaf type provides support for species sorting. Beta diversity explained by depth could support either dispersal limitation or species sorting, as would the case where spatial effects and leaf type cannot be disentangled. All statistical tests were conducted using the vegan package (Oksanen 2005) in R using 999 random permutations of sample identity. Fungal community composition was represented by Hellinger-transformed TRF relative abundance data (Legendre \& Gallagher 2001).

At each site, we utilized Mantel analysis (Mantel 1967) to test for a significant linear distance-decay relationship by testing for a correlation between spatial distance and Hellinger distance between TRFLP profiles. Mantel analysis using a spatial distance matrix is a direct test of the effect of geographic structure on community composition (Borcard \& Legendre 2002). Mantel analysis was performed using both stepwise and weighted spatial distances, excluding nonconnected leaves. We also conducted Mantel analysis to assess whether fungal community composition was correlated with the environmental variables leaf type and depth within the forest floor. Finally, where multiple explanatory factors were found to be significant, we conducted partial Mantel analysis to separate the influence of the different factors.
Spatial distance matrices were also used to calculate principle coordinates of neighbour matrices (PCNM) vectors using the R package PCNM (Borcard \& Legendre 2002). PCNM vectors are orthogonal explanatory variables designed to represent the entire range of potential spatial structures that could be found within a spatial distance matrix (Borcard et al. 2004). We conducted RDA at each site on all leaves corresponding with leaf types collected more than twice (i.e. excluding singleton or doubleton leaf types). RDA was used to test whether spatial location (represented by PCNM vectors), leaf type or depth explained fungal community composition. If a preliminary analysis indicated that PCNM vectors explained significant variation, forward selection was conducted to select a group of parsimonious PCNM vectors to help mitigate type I errors and avoid an overestimation of the amount of explained variance (Blanchet et al. 2008). If multiple explanatory factors were significant, variance partitioning (PeresNeto et al. 2006) was used to determine the relative amount of variance explained by each variable and the interactive effect between the variables. Variance partitioning allowed us to determine whether the impact of variables such as depth and PCNM were independent or embedded within each other.

Collector's curve analysis. We conducted collector's curve analysis on all leaves at a site to determine whether 
community composition stabilizes with increased sampling of leaf habitat patches. Collector's curves were generated by artificially sampling leaves at a given site using 99 randomly generated leaf addition sequences (Coleman 1981; Colwell \& Coddington 1994). Collector's curves were analysed using two indices. The first index was the total number of TRFs detected at the site, and the collector's curve using this index indicates the number of leaves required to sample all TRFs within a set of leaves. The second index was the Hellinger distance between each new leaf and the average community composition of the previous set of leaves, which we call 'sample-to-centroid distance'. This collector's curve indicates the number of samples required to approximate the average (or centroid) community composition of a set of leaves. To determine whether patterns in collector's curves were associated with depth, we also ran the analysis by stratifying the leaf addition sequence randomization by depth.

Analysis of variation across sites. RDA was also conducted on all communities combined into one data set to test for significant effects of the factors at the landscape scale, forest habitat type and site nested within habitat, as well as leaf type. This analysis was conducted after leaf types collected only once or twice were removed (resulting in $n=160$ ) because the site factor would necessarily explain all or most of the variance associated with these species. We also conducted this analysis using only maple and beech leaves $(n=130)$, which were well represented at every site.

To compare $\beta$-diversity among sites, we utilized Anderson's multivariate homogeneity of group dispersion test (Anderson et al. 2006). The test was performed for all beech and maple leaf communities based on Hellinger distance. This analysis calculates the distance in multivariate space of each leaf community from the site centroid and uses an ANOVA framework to test whether group dispersions from various sites are significantly different. Differences were visualized using nonmetric multidimensional scaling plots based on Hellinger distance.

Comparison of TRFLP with operational taxonomic units data. Ordination of TRFLP profiles from 24 samples was compared to ordination of the same samples based on ITS sequences clustered into operational taxonomic units (OTU). Detailed methods and analyses for the sequence data are reported in Feinstein \& Blackwood (2012). These samples included the largest and smallest beech leaves collected from each site. Hellinger distance matrices were computed from TRFLP and OTU relative abundances, and Mantel and Procrustes analyses were used as complementary methods to compare the relationships among communities in the TRFLP and OTU data sets (Legendre \& Legendre 1998; Peres-Neto \& Jackson 2001). In addition, the variance explained by site and leaf type in both data sets was determined by RDA. Relationships among treatments captured in canonical RDA axes were then compared with both Mantel and Procrustes analyses, as were the residual RDA axes.

\section{Results}

\section{Distance decay and Mantel analyses within sites}

Mantel analysis indicated that fungal community composition similarity decreased with spatial distance at all sites except one upland site $(P<0.05$; Fig. 2$)$. This pattern was consistent for spatial distance measured as either number of steps or weighted distance across the leaf networks. Mantel analysis also indicated that depth had a significant effect on fungal community composition at all of the same sites that a significant distance decay was found (Table 1), indicating that fungal community composition differs among layers within the forest floor. In contrast to the effects of spatial distance and depth, Mantel analysis for leaf type was only significant at one vernal pool site (Table 1).

Partial Mantel analysis showed that depth and spatial distance were often embedded within each other and their relative importance could not be easily disentangled (Table 1). At two sites (vernal pool-J3 and uplandL6) spatial distance was not significant after correction by depth. However, the opposite pattern was found at site riparian-J1. At two sites (vernal pool-H6 and riparian-Q1) both spatial distance and depth were still significant after correction for the other factor. These patterns were consistent for both step- and weighted distance. Partial Mantel analysis at the one site with a significant leaf type Mantel correlation indicated that leaf type remained significant after correction for step distance, but not weighted distance.

\section{RDA of fungal community composition within leaf networks}

Fungal communities at all sites except for one were affected by spatial location, as indicated by a significant effect of step-distance PCNM vectors, weighted-distance PCNM vectors or both (Table 2). Significant step-distance PCNM vectors explained $7.8-12.3 \%$ of the variance in fungal community composition among leaves at three sites, while weighted-distance PCNM vectors explained $6.8-16.1 \%$ of the variance at four sites (Table 2). Leaf type had a significant effect on fungal community composition at four sites, explaining between $2.6 \%$ and $6.5 \%$ of 

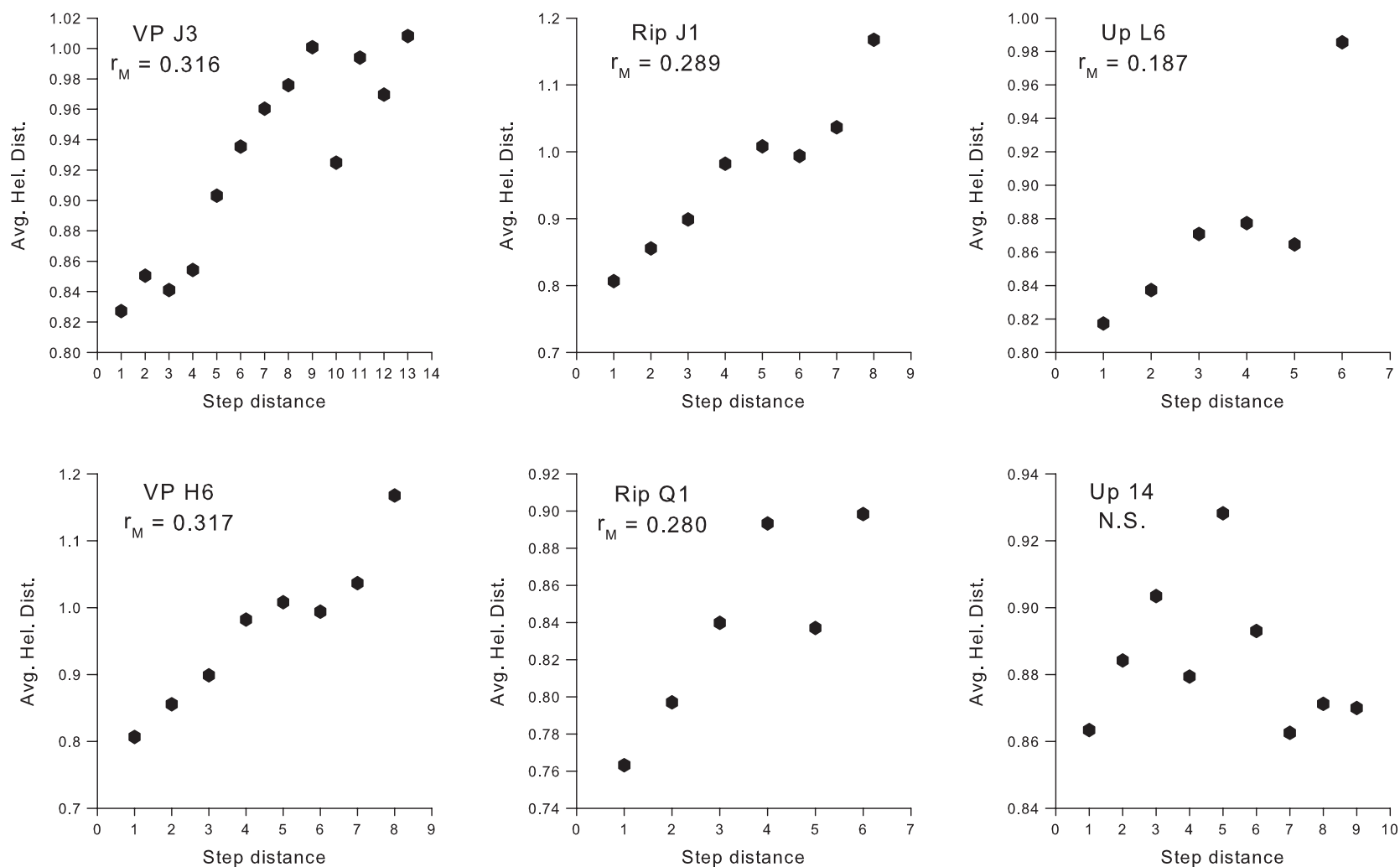

Fig. 2 Distance-decay plots showing the average Hellinger distance between communities at increasing step distances for each of the six sites in this study. Habitat abbreviations (VP, vernal pool; Rip, riparian; Up, upland), site ID and the standardized Mantel statistic $\left(r_{\mathrm{M}}\right)$ are shown for each plot.

Table 1 Mantel correlation $\left(r_{\mathrm{M}}\right)$ values between fungal community composition and spatial distance (step or weighted), leaf depth and leaf type for all connected leaves

\begin{tabular}{|c|c|c|c|c|c|c|}
\hline & VP J3 & VP H6 & Rip J1 & Rip Q1 & Up L6 & Up 14 \\
\hline Step distance & $0.29 * * *$ & $0.32^{* * *}$ & $0.32^{* * *}$ & $0.28^{* *}$ & $0.19^{*}$ & NS \\
\hline Step I type & $0.28^{* * *}$ & $0.32^{* * *}$ & $0.32^{* * *}$ & $0.29 * *$ & $0.18^{* *}$ & NS \\
\hline Step I depth & NS & $0.29^{* * *}$ & $0.30^{* * *}$ & $0.20^{*}$ & NS & NS \\
\hline Depth & $0.33^{* * *}$ & $0.19^{* * *}$ & $0.11^{*}$ & $0.42^{* * *}$ & $0.24^{* *}$ & NS \\
\hline Depth I step & $0.18^{* *}$ & $0.13^{* *}$ & NS & $0.38^{* * *}$ & $0.18^{* *}$ & NS \\
\hline Type & NS & $0.16^{*}$ & NS & NS & NS & NS \\
\hline Type I step & NS & $0.16^{*}$ & NS & NS & NS & NS \\
\hline Weighted distance & $0.23^{* * *}$ & $0.29^{* * *}$ & $0.26^{* * *}$ & $0.33^{* * *}$ & $0.23^{* * *}$ & NS \\
\hline Wt I type & $0.22^{* * *}$ & $0.29^{* *}$ & $0.26^{* * *}$ & $0.34^{* *}$ & $0.17^{* *}$ & NS \\
\hline Wt I depth & NS & $0.27^{* *}$ & $0.25^{* * *}$ & $0.24^{* *}$ & NS & NS \\
\hline Depth & $0.33^{* * *}$ & $0.19^{* * *}$ & $0.11^{*}$ & $0.42^{* * *}$ & $0.24^{* *}$ & NS \\
\hline Depth I wt & $0.24^{* * *}$ & $0.14^{* *}$ & NS & $0.36^{* * *}$ & $0.20^{* *}$ & NS \\
\hline Type & NS & $0.16^{*}$ & NS & NS & NS & NS \\
\hline Type I wt & NS & NS & NS & NS & NS & NS \\
\hline$n$ & 30 & 29 & 30 & 15 & 20 & 30 \\
\hline
\end{tabular}

Partial Mantel analysis was performed to test the effect of one matrix (before the ' $\mid$ ') after correcting for effects of various distance matrices (after the ' $\mid$ '). Nonconnected leaves were removed before analysis.

Statistical significance is shown with the following symbols: $* P<0.1 ; * * P<0.05 ; * * * P<0.01$; NS, not significant. 
Table 2 Proportion of variance (adjusted $R^{2}$ ) in fungal community composition at each site explained by spatial location (PCNM vectors selected after forward selection), leaf depth and leaf type

\begin{tabular}{|c|c|c|c|c|c|c|c|}
\hline \multirow[b]{2}{*}{ Site } & \multirow[b]{2}{*}{$n$} & \multirow[b]{2}{*}{ Leaf type } & \multirow[b]{2}{*}{ Depth } & \multicolumn{2}{|l|}{ Step } & \multicolumn{2}{|c|}{ Weighted } \\
\hline & & & & PCNM & Full model & PCNM & Full model \\
\hline VP J3 & 21 & NS & $0.15^{* * *}$ & $0.12^{* * *}$ & 0.16 & $0.15^{* * *}$ & 0.20 \\
\hline VP H6 & 20 & $0.05^{* *}$ & $0.03^{*}$ & $0.08^{* *}$ & 0.13 & NS & 0.07 \\
\hline Rip J1 & 25 & $0.03^{*}$ & $0.06^{* * *}$ & $0.12^{* * *}$ & 0.15 & $0.15^{* * *}$ & 0.15 \\
\hline Rip Q1 & 6 & NS & NS & NS & 0.00 & $0.16^{* *}$ & 0.16 \\
\hline Up L6 & 19 & $0.07^{* *}$ & $0.03^{* *}$ & NS & 0.10 & NS & 0.10 \\
\hline Up 14 & 20 & $0.04^{* *}$ & NS & NS & 0.04 & $0.07^{* *}$ & 0.08 \\
\hline
\end{tabular}

RDA conducted on beech and maple leaves that were within a connected leaf network (n). Full model shows the total amount of variance explained by all significant factors using either step- or weighted distance (full models were always significant).

$* P<0.1 ; * * P<0.05 ; * * * P<0.01$; NS, not significant.

the variance between leaves at one riparian, one vernal pool and both upland sites (Table 2). Depth had a significant effect on fungal community composition at four sites, explaining 3.3-15.3\% of the variance. Similar to the results of partial Mantel analysis, partial RDA showed that the influence of spatial distance, depth and leaf type could sometimes not be disentangled. This is indicated when the variance explained by all significant factors was less than the sum of the variances explained by each factor alone (Table 2).

\section{Collector's curve analysis}

When fungal communities were sampled in a random order, community composition at the upland and vernal pool sites stabilized after sampling approximately 10 leaves, as indicated by both the total number of TRFs detected and the sample-to-centroid distance (Figs 3 and 4). When randomization of leaves was stratified by depth, the trajectory of the collector's curves shifted most dramatically at vernal pool sites. The number of TRFs detected rapidly increased within the first and third or fourth layers, but other layers were not as distinct and resulted in little increase in the number of TRFs detected (Fig. 3). This is also clear from the vernal pool sample-to-centroid distance plots, in which samples from new depths are increasingly distant from the centroid of previous depths (Fig. 4). Stratifying by depth in the upland sites did not impact the shape of the collector's curves, whereas the impact of depth was intermediate for riparian sites. Collector's curves stratified by leaf type did not differ substantially from the nonstratified curves, except in a few cases of leaf types that were not well represented at any given site (data not shown). The sample-to-centroid distance stabilized at the highest value at riparian site J1 (0.75), indicating that the communities within this site had the highest beta diversity, which was also confirmed by the
Anderson homogeneity of group dispersion test discussed below.

\section{Comparison of $\beta$-diversity among forest sites}

In a pooled analysis of leaves across all sites, forest habitat, sites nested within habitats, depth and leaf type explained significant variation in fungal community composition across the forest, although habitat type clearly explained the largest amount of variance (Table 3). This pattern was apparent in analyses of all leaves except singletons and doubletons and in beech and maple leaves only. Principal coordinate analysis (Fig. 5) indicates that fungal communities on leaves in the vernal pool sites were particularly different from the upland and riparian sites. The effect of site nested within habitat type was strongest in riparian forest, with the riparian forest sites separated by the second principal coordinate axis (Fig. 5). The differences between beech and maple leaves, as well as between depths (not shown), were too minor to be reflected in the first two ordination axes.

The magnitude of $\beta$-diversity within a site, measured as the multivariate dispersion among leaves at a site (i.e. average distance to the site centroid), significantly differed among habitats and sites across the forest $(P<0.001)$. $\beta$-Diversity $( \pm S D)$ was lower in the upland $(0.613 \pm 0.007)$ and vernal pool sites $(0.629 \pm 0.003)$ than in the riparian sites $(0.641 \pm 0.081)$. One riparian site (J1), in particular, had the highest beta diversity and more variable fungal communities than all other sites, with communities resembling those found on leaves from both upland sites and the other riparian site (Fig. 5).

\section{Comparison of TRFLP with OTU data}

Mantel and Procrustes analyses indicated that relationships among samples characterized by both TRFLP 

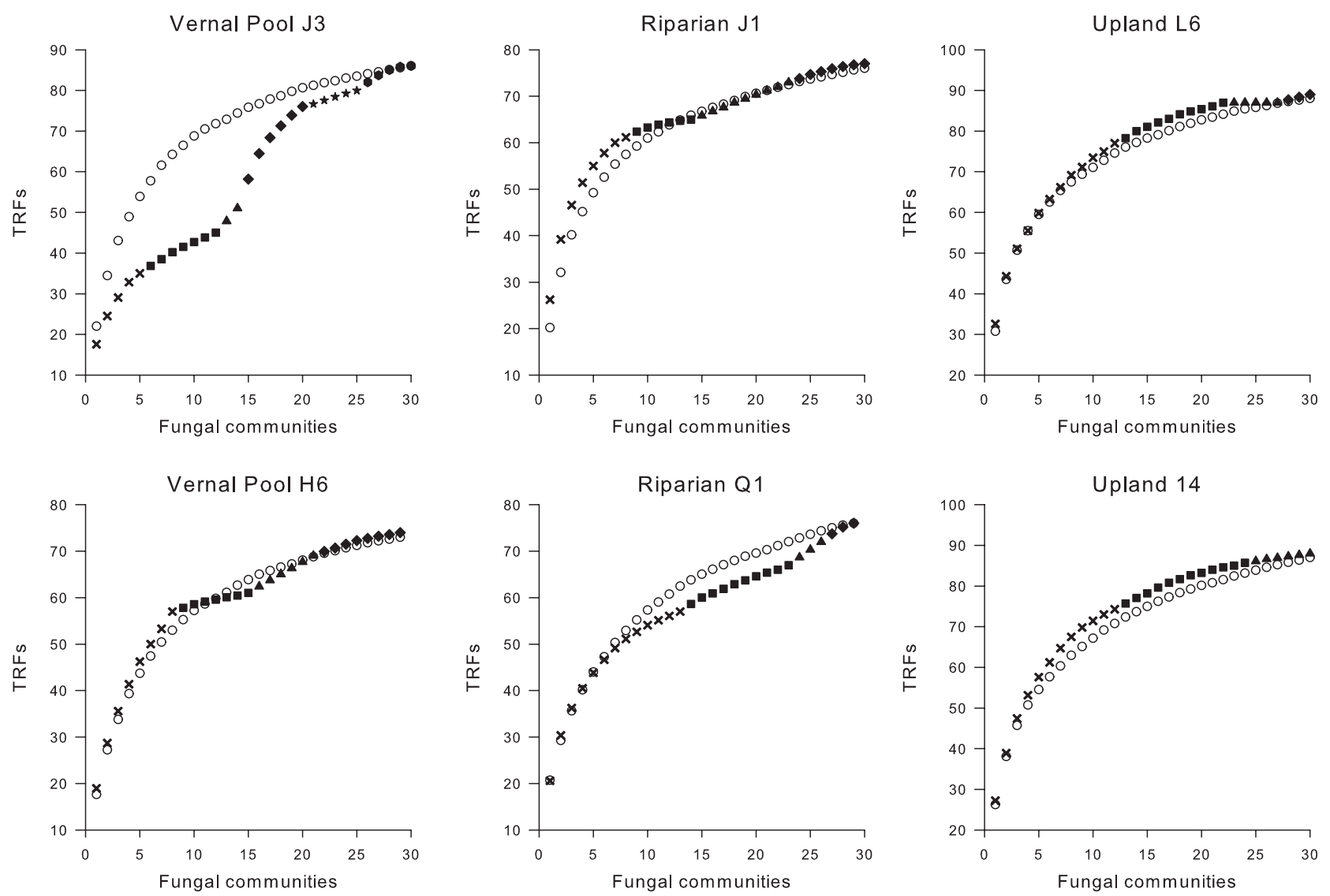

Fig. 3 Collector's curve analysis quantifying new TRFs with each randomly selected fungal community. Plots show the set of all randomly selected communities at each site (white circles) and communities randomly selected at each depth within the forest floor leaf pack that the communities were located in (black symbols). Symbols for layers of the leaf pack that communities were sampled from: first (top) layer: $x$; second layer: square; third layer: triangle; fourth layer: diamond; fifth layer: star; sixth layer: circle.

and sequence-based OTU were significantly similar $\left(r_{\mathrm{M}}=0.49\right.$ and Procrustes correlation $=0.9, \quad P<0.001$ for both). RDA indicated that site explained $22.5 \%$ of the variation in TRFLP profiles and $26.6 \%$ of the variation in OTU abundances, while leaf type explained $2.3 \%$ of the variation in both data sets. The relationships among treatments revealed by TRFLP and OTU were almost identical, with very high correlations between canonical axes $\left(r_{\mathrm{M}}=0.94\right.$ and Procrustes correlation $=0.97, P<0.001$ for both). The relationships among communities captured in residual axes were also quite similar between the two analyses methods $\left(r_{\mathrm{M}}=0.58\right.$ and Procrustes correlation $=0.92, P<0.001$ for both).

\section{Discussion}

\section{Fungal distance decay}

A primary objective of this work was to quantify fungal diversity patterns at multiple spatial scales. One pattern that has been commonly described in ecology is the distance-decay pattern (Nekola \& White 1999), where community similarity decreases at increasing spatial distance. We utilized the discrete nature of senesced leaf habitat patches to quantify individual fungal communities and construct spatial distance matrices to determine whether fungi would follow a distance-decay pattern. At five of the six sites sampled, we found a distance-decay relationship where community distance was significantly correlated with spatial distance across 30 local communities located within a $850-\mathrm{cm}^{2}$ plot. Although previous studies have mapped fungi on the forest floor at small scales (Frankland 1998; Boddy et al. 2009), we are unaware of previous attempts to examine fungal community distance decay in this habitat, and most previous studies in mineral soil have quantified distance decay in fungal communities at much larger spatial scales. Green et al. (2004) found a distance-decay pattern in soil fungi in arid Australian habitat across distances ranging from 1 to $10^{10} \mathrm{~m}^{2}$. Distance decay was also detected for arbuscular mycorrhizal fungi colonizing Allium cepa roots growing in soil cores collected from $100-\mathrm{m}^{2}$ plots separated by up to $250 \mathrm{~km}$ (van der 

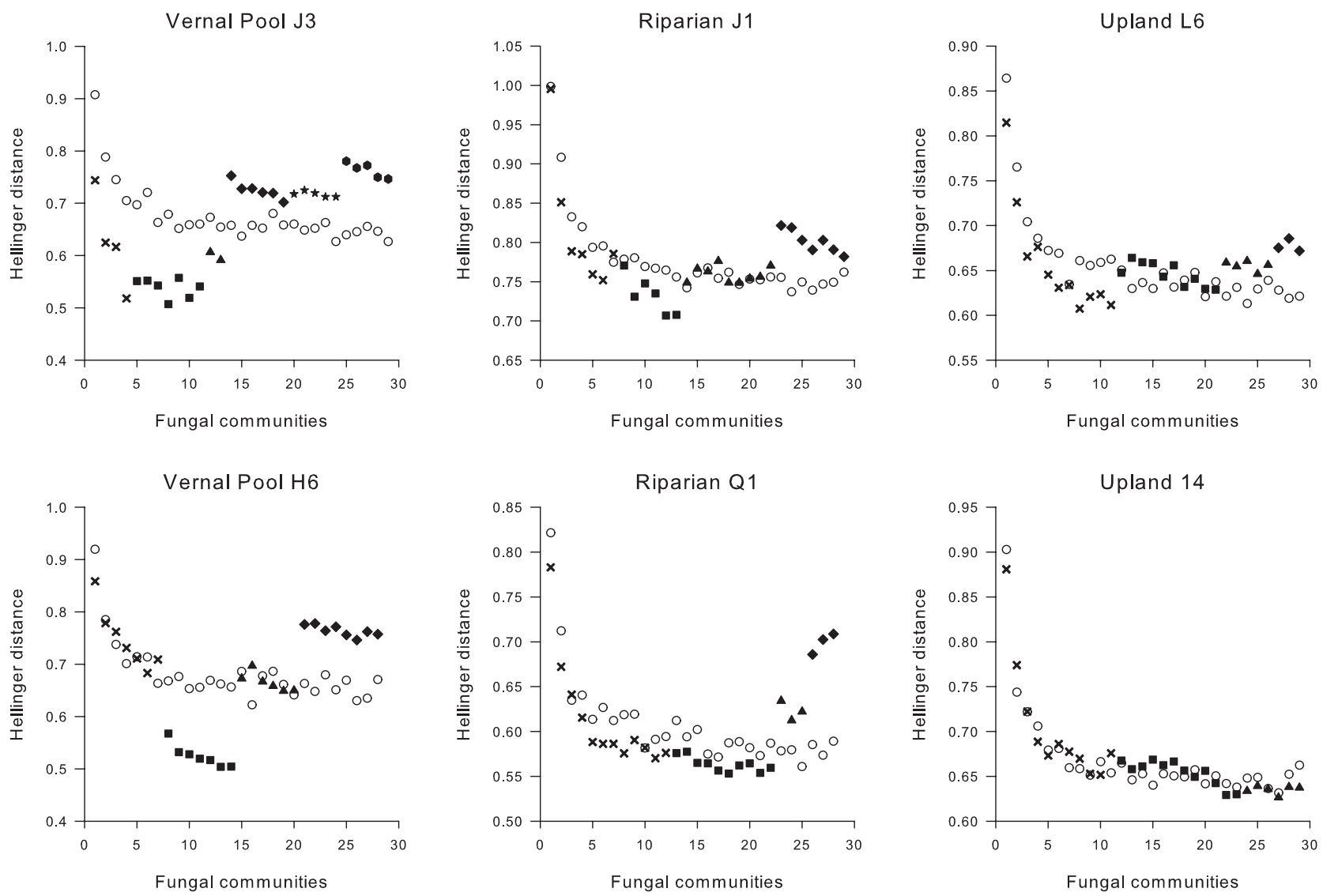

Fig. 4 Collector's curve analysis quantifying the difference between new and previous fungal community composition. The community composition with each additional leaf contributes to a site centroid composition value, and the composition of each new community is then compared to the site centroid value. Plots show the set of all randomly selected communities at each site (white circles) and communities randomly selected at each depth within the forest floor leaf pack that the communities were located in (black symbols). Symbols for layers of the leaf pack that communities were sampled from: first (top) layer: $x$; second layer: square; third layer: triangle; fourth layer: diamond; fifth layer: star; sixth layer: circle.

Table 3 RDA of community composition across all sites for all beech $(n=70)$ and maple $(n=60)$ leaves or all leaves $(n=160)$ after singleton and doubleton species at each site were removed

\begin{tabular}{llllll}
\hline & \multicolumn{2}{l}{$\begin{array}{l}\text { Beech } \\
\text { only }\end{array}$} & & & \multicolumn{2}{l}{ And Maple } & \\
\cline { 2 - 3 } \cline { 5 - 6 } Test variable & $P$-value & Adj. $R^{2}$ & & $P$-value & Adj. $R^{2}$ \\
\hline Habitat & 0.005 & 0.18 & & 0.005 & 0.18 \\
Site & 0.005 & 0.07 & & 0.005 & 0.04 \\
Leaf type & 0.010 & 0.01 & & 0.010 & 0.02 \\
Site $\times$ leaf type & 0.005 & 0.02 & & NA & NA \\
Depth & 0.005 & 0.02 & & 0.005 & 0.02 \\
\hline
\end{tabular}

The site $\times$ leaf type interactions were not tested for all leaves due to the complete absence of several leaf types from some sites.
Gast et al. 2011). However, no evidence of distance decay was found by Robinson et al. (2009) working in grassland soil at the scale of $25 \mathrm{~cm}$ to $96 \mathrm{~m}$ or by Zinger et al. (2011) working in a variety of habitats separated by $100 \mathrm{~m}$ to $2 \mathrm{~km}$ in the Alps. In contrast to these previous studies, we examined connected networks of leaves where individuals or populations had direct physical access to each habitat patch and where dispersal limitation and habitat heterogeneity seem less likely to be potentially important factors. However, here we provide evidence for the first time that distance decay is operational in fungal communities located on discrete, but adjacent, habitat patches.

\section{Influencing distance decay: species sorting and dispersal limitation}

We attempted to quantify the relative influence of species sorting and dispersal limitation on the distance-decay 




Fig. 5 Ordination of TRFLP profiles (community composition) for all fungal communities found on beech $(n=70)$ and maple $(n=60)$ leaves. The large open symbols represent centroids in multivariate space for the communities found at a site. The terminus of each line emanating from the centroid represents one leaf ( $\times$ symbols indicate maple leaves; $\Delta$ symbols indicate beech leaves). Site community compositions are significantly different $(P<0.001)$.

relationship and $\beta$-diversity detected in fungal communities on leaves. However, because variance in community composition explained by spatial distance could also be largely explained by depth within the forest floor, species sorting and dispersal limitation factors could not be unambiguously disentangled. This confounding of spatial distance with environmental variation is not uncommon (Astorga et al. 2012) and has been described in the understory vegetation of a temperate forest similar to the one we worked in (Gilbert \& Lechowicz 2004). Overlap in variance explained by these factors may indicate that both species sorting and dispersal limitation are important, as has been shown previously for arbuscular mycorrhizal communities (Dumbrell et al. 2010), fermentative bacterial communities (Boyd et al. 2010), atmospheric bacteria colonizing new sterile habitat (Langenheder and Székely 2011) and soil bacterial communities (Hovatter et al. 2011).

\section{The impact of environmental heterogeneity on community composition}

The link between environmental heterogeneity and biological diversity has been described as being operational at all levels of ecological organization (Townsend \& Fuhlendorf 2010) to the point where heterogeneity should serve as a foundation for conservation and ecosystem management (Christensen 1997; Wiens 1997). We found evidence that environmental heterogeneity may influence fungal community composition at spatial scales ranging from across the landscape to within an individual sampling site. At the larger landscape scale, we found that vernal pool fungal communities were particularly different than fungi in upland and riparian habitat (Fig. 5). This pattern provides evidence that at a landscape scale, fungal community composition is generally filtered by species-sorting processes, most likely associated with seasonal completely saturated conditions that typify vernal pools and are not found in either upland or riparian sites.

Environmental heterogeneity located within sampling sites is potentially associated with leaf type and the depth at which a leaf is found. We were surprised to find that leaf type had only a small effect on fungal community composition, despite sampling leaves that should differ dramatically in lignin content. Lignin is efficiently degraded by a small subset of micro-organisms, and variations in lignin contents have been proposed to be associated with microbial community succession during litter degradation (Moorhead \& Sinsabaugh 2006; Theuerl \& Buscot 2006). However, our study, coupled with the results of Wu et al. (2011) at the same site, indicates that other factors may exert stronger control over fungal community composition in the forest floor. Depth of a leaf within the Oi horizon is probably related to a variety of environmental variables that may affect fungal community composition, including moisture and access to nutrients in the mineral soil (Heal et al. 1997; Bjrnlund \& Christensen 2005). Differences between fungal communities located in adjacent layers of the leaf pack were most pronounced in the riparian and vernal pool habitats (Figs 4 and 5), habitats with greater moisture heterogeneity than the upland. An increase in moisture has been associated with increased fungal richness in tropical (Braga-Neto et al. 2008) and boreal (Przybyl et al. 2008) leaf litter. We also noted during leaf collection that vernal pool leaves were mixed with watersaturated mineral soil, which was removed during sampling, but may cause the lower layers of the leaf pack to be more compact (Rinklebe \& Langer 2006) and prone to anaerobiosis.

Lower environmental heterogeneity at upland sites may help explain why community composition in this habitat was the most stable and least influenced by distance-decay spatial effects (Figs 4 and 5). The leaf litter was dominated by beech and maple at these sites, and to collect the necessary 30 leaves, we did not need to sample as deeply into the forest floor as we did at vernal pool and riparian sites. The upland sites were also elevated and exposed to windier conditions than either the 
riparian or vernal pool sites. Wind may mix leaves more frequently in the upland, disturbing the arrangement of adjacent habitat patches. The wind and shallower depth of leaves collected may have caused upland leaves to be drier than those in riparian sites (and certainly than those in vernal pools). Dry conditions slow the growth of fungal hyphae (Hawkes et al. 2011), which would inhibit spread of fungi among leaves.

\section{The impact of colonization on community composition}

Beta diversity of fungal communities at this scale is probably influenced by two different pools of fungal colonizers. Deep leaves within the leaf pack are in contact with the Oe and A horizons and are likely to be colonized by soil fungi (Smith \& Bradford 2003; Carillo et al. 2011). Soil is a microscopically heterogeneous matrix of organic and inorganic material (Pajor et al. 2010), with varying water and oxygen availability creating spatially separated aerobic and anaerobic niches (Young \& Crawford 2004; Or et al. 2007). These heterogeneous conditions in soil are thought to be responsible for the extremely high bacterial diversity that has been quantified in soil (Curtis \& Sloan 2005; Gans et al. 2005). In contrast, leaf litter is mostly organic and aerobic (except seasonally in vernal pools), and the fungal diversity of litter relative to soil has not been quantified (Hyde et al. 2007).

In addition to colonization via hyphal growth that we would expect from fungi in adjacent leaf litter and soil, fungi may also disperse over relatively long distances via spores (Boddy et al. 2008). Some fungi have been documented to have generalist strategies and are capable of existing in very different environmental conditions due to their ability to adapt to a wide variety of environmental factors (Cantrell et al. 2011). Spores may be ejected into the air quite forcefully (Trail 2007), and studies have shown that spores could be expected to easily disperse over the distances between our sites (Stockmarr et al. 2007; Boddy et al. 2009). It is possible that several leaves located in very different habitats (vernal pool and upland) had very similar community compositions (Fig. 6) because of colonization from spores and subsequent priority effects. To quantify the influence of spore colonization compared to colonization from adjacent leaf litter and soil, changes in community composition over time would have to be quantified in these different microsites.

\section{Variations in fungal beta diversity}

Site beta diversity was very different in the two riparian sites, with one site (riparian-J1) having the highest and one site (riparian-Q1) having the lowest beta diversity found among all sites (Fig. 6). In a complementary study, $75 \%$ of the leaf communities that were surveyed at the site with the lowest beta diversity (Q1) were dominated by one sequence-based OTU within the genus Mycena (Feinstein \& Blackwood 2012). Aggressive growth of this fungus may be responsible for the low beta diversity that we found at that site. Riparian areas in general are characterized by a high degree of environmental variability including localized patches of nutrients (Liu et al. 2008) and moisture saturation (Douglas et al. 2005), which may affect fungal community diversity (Rinklebe \& Langer 2006). Hence, it is also possible that the difference in beta diversity associated with the two riparian sites in this study could be related to localized environmental heterogeneity between riparian sites.

\section{Comparison of ordinations of TRFLP with sequence information}

In this study we have described close correlation between ordinations generated from TRFLP data and sequences obtained from clone libraries, validating the TRFLP methodology we employed. We used relative abundance of TRFs calculated from peak height because this procedure has been repeatedly validated as a sensitive and robust measure of microbial community composition (e.g. Blackwood et al. 2003; Blackwood \& Buyer 2007). Culman et al. (2008) made a direct comparison between peak height and peak area and found that the results were almost identical, but recommended use of peak height because of greater sensitivity.

\section{Conclusion}

The significant distance-decay relationships that were found in this study are the first to be quantified at the scale of spatial networks of adjacent leaves. Although leaves of different tree species are known to have differing amounts of biochemical resources, which affects decomposition rate and microbial metabolism, leaf type had a relatively small effect on fungal community composition. However, because we found differences among communities associated with depth and habitat type, fungal community composition was shown to be potentially associated with other types of environmental heterogeneity at landscape and local scales. In our sampling design it was not possible to disentangle the influence of these factors from dispersal limitation, which should be addressed in future studies. Although fungal community composition may be characterized at upland and vernal pool sites by quantifying communities on 10 leaves, it is clear that the sampling of depths (leaf layers) within the Oi horizon will have an impact on patterns in community composition. 


\section{Acknowledgements}

This research was funded through Kent State University startup funding provided to C.B.B. and grants to L.M.F. from the Kent State University Graduate Student Senate and Department of Biological Sciences Arthur \& Margaret Herrick fund. We would like to thank Alex Gradisher and Melissa Brewster for laboratory assistance.

\section{References}

Anderson MJ, Ellingsen KE, McArdle BH (2006) Multivariate dispersion as a measure of beta diversity. Ecology Letters, 9, 683-693.

Astorga A, Oksanen J, Luoto M, Soininen J, Virtanen R, Muotka T (2012) Distance decay of similarity in freshwater communities: do macro- and microorganisms follow the same rules? Global Ecology and Biogeography, 21, 365-375.

Berg B, Laskowski R (2006) Litter Decomposition: A Guide to Carbon and Nutrient Turnover, pp. 448. Elsevier, Burlington, MA, USA.

Bjrnlund L, Christensen S (2005) How does litter quality and site heterogeneity interact on decomposer food webs of a semi-natural forest? Soil Biology and Biochemistry, 37, 203-213.

Blackwood CB, Buyer JS (2007) Evaluating the physical capture method of terminal restriction fragment length polymorphism for comparison of soil microbial communities. Soil Biology and Biochemistry, 39, 590-599.

Blackwood CB, Marsh T, Kim SH, Paul EA (2003) Terminal restriction fragment length polymorphism data analysis for quantitative comparison of microbial communities. Applied and Environmental Microbiology, 69, 926-932.

Blanchet FG, Legendre P, Borcard D (2008) Forward selection of explanatory variables. Ecology, 89, 2623-2632.

Boddy L, Frankland JC, van West P (eds) (2008) Ecology of Saprotrophic Basidiomycetes, Vol. 28, pp. 386. Academic Press, Amsterdam.

Boddy L, Hynes J, Bebber DP (2009) Saprotrophic cord systems: dispersal mechanisms in space and time. Mycoscience, 50, 9-19.

Borcard D, Legendre P (2002) All-scale spatial analysis of ecological data by means of principal coordinates of neighbour matrices. Ecological Modelling, 153, 51-68.

Borcard D, Legendre P, Avois-Jacquet C, Tuomisto H (2004) Dissecting the spatial structure of ecological data at multiple spatial scales. Ecology, 85, 1826-1832.

Boyd E, Hamilton T, Spear J, Lavin M, Peters J (2010) [FeFe]hydrogenase in Yellowstone National Park: evidence for dispersal limitation and phylogenetic niche conservatism. ISME Journal, 4, 1485-1495.

Braga-Neto R, Luizao RCC, Magnusson WE, Zuquim G, De Castilho CV (2008) Leaf litter fungi in a Central Amazonian forest: the influence of rainfall, soil and topography on the distribution of fruiting bodies. Biodiversity and Conservation, 17, 2701-2712.

Brose U, Ostling A, Harrison K, Martinez ND (2004) Unified spatial scaling of species and their trophic interactions. Nature, 428, 167-171.

Cantrell SA, Dianese JC, Fell J, Gunde-Cimerman N, Zalar P (2011) Unusual fungal niches. Mycologia, 103, 1161-1174.
Carillo Y, Ball BA, Bradford MA, Jordan CF, Molina M (2011) Soil fauna alter the effects of litter composition on nitrogen cycling in a mineral soil. Soil Biology and Biochemistry, 43, 1440-1449.

Christensen NL (1997) Managing for heterogeneity and complexity on dynamic landscapes. In: The Ecological Basis for Conservation: Heterogeneity, Ecosystems, and Biodiversity (eds Pickett STA, Ostfeld RS, Shachak M, Likens GE), pp. 167-186. ????, New York, NY.

Coleman BD (1981) On random placement and species-area relations. Mathematical Biosciences, 54, 191-215.

Colwell RK, Coddington JA (1994) Estimating terrestrial biodiversity through extrapolation. Philosophical Transactions of the Royal Society Series B: Biological Sciences, 345, 101-118.

Cornwell WK, Cornelissen JHC, Amatangelo K et al. (2008) Plant species traits are the predominant control on litter decomposition rates within biomes worldwide. Ecology Letters, 11, 1065-1071.

Culman SW, Gauch HG, Blackwood CB, Thies JE (2008) Analysis of T-RFLP data using analysis of variance and ordination methods: a comparative study. Journal of Microbiological Methods, 75, 55-63.

Curtis TP, Sloan WT (2005) Exploring microbial diversity - a vast below. Science, 309, 1331-1333.

Douglas MM, Bunn SE, Davies PM (2005) River and wetland food webs in Australia's wet-dry tropics: general principles and implications for management. Marine Freshwater Research, 56, 329-342.

Dumbrell AJ, Nelson M, Helgason T, Dytham C, Fitter AH (2010) Relative roles of niche and neutral processes in structuring a soil microbial community. ISME Journal, 4, 337-345.

Ellson J, Gansner E, Koutsofios L, North SC, Woodhull G (2000) Graphviz-open source graph drawing tools. Lecture Notes in Computer Science, 2265, 594-597.

Feinstein LM, Blackwood CB (2012) Taxa-area relationship and neutral dynamics influence the diversity of fungal communities on senesced tree leaves. Environmental Microbiology, 14, 1488-1499.

Fierer N, Breitbart M, Nulton J et al. (2007) Metagenomic and small-subunit rRNA analyses reveal the genetic diversity of Bacteria, Archaea, Fungi, and viruses in soil. Applied and Environmental Microbiology, 73, 7059-7066.

Filotas E, Grant M, Parrott L, Rikvold PA (2010) Positive interactions and the emergence of community structure in metacommunities. Journal of Theoretical Biology, 266, 419-429.

Frankland JC (1998) Fungal succession - unravelling the unpredictable. Mycological Research, 102, 1-15.

Fukami T, Dickie IA, Wilkie JP et al. (2010) Assembly history dictates ecosystem functioning: evidence from wood decomposer communities. Ecology Letters, 13, 675-684.

Gans J, Wolinsky M, Dunbar J (2005) Computational improvements reveal great bacterial diversity and high metal toxicity in soil. Science, 309, 1387-1390.

van der Gast CJ, Gosling P, Tiwari B, Bending GD (2011) Spatial scaling of arbuscular mycorrhizal fungal diversity is affected by farming practice. Environmental Microbiology, 13, 1462-2920.

Gilbert B, Lechowicz MJ (2004) Neutrality, niches, and dispersal in a temperate forest understory. Proceedings of the National Academy of Sciences of the United States of America, 101, 7651-7656. 
Gotelli N, Colwell RK (2001) Quantifying biodiversity: procedures and pitfalls in the measurement and comparison of species richness. Ecology Letters, 4, 379-391.

Gravel D, Canham CD, Beaudet M, Messier C (2006) Reconciling niche and neutrality: the continuum hypothesis. Ecology Letters, 9, 399-409.

Green J, Bohannan BJM (2006) Spatial scaling of microbial biodiversity. Trends in Ecology and Evolution, 21, 501-507.

Green JL, Holmes AJ, Westoby M et al. (2004) Spatial scaling of microbial eukaryote diversity. Nature, 432, 747-750.

Hawkes CV, Kivlin SN, Rocca JD, Huguet V, Thomsen MA, Suttle KB (2011) Fungal community responses to precipitation. Global Change Biology, 17, 1637-1645.

Heal OW, Anderson JM, Swift MJ (1997) Plant litter quality and decomposition: an historical overview. In: Driven by Nature (eds Cadisch G \& Giller KE), pp. 3-30. CAB International, Cambridge, UK.

Helgason T, Merryweather JW, Denison J, Wilson P, Young JPW, Fitter AH (2002) Selectivity and functional diversity in arbuscular mycorrhizas of co-occurring fungi and plants from temperate deciduous woodland. Journal of Ecology, 90, 371-384.

Holt RD (2002) Food webs in space: on the interplay of dynamic instability and spatial processes. Ecological Research, 17, 261-273.

Hovatter S, Dejelo C, Case AL, Blackwood CB (2011) Metacommunity organization of soil microorganisms depends on habitat type defined by presence of Lobelia siphilitica plants. Ecology, 92, 57-65.

Hubbell SJ (2001) The Unified Neutral Theory of Biodiversity and Biogeography, pp. 448. Princeton University Press, Princeton, NJ.

Hyde KD, Bussaban B, Paulus B et al. (2007) Diversity of saprobic microfungi. Biodiversity and Conservation, 16, 7-35.

Jabot F, Bascompte J (2012) Bitrophic interactions shape biodiversity in space. Proceedings of the National Academy of Sciences of the United States of America, 109, 4521-4526.

Kivlin SN, Hawkes CV, Treseder KK (2011) Global diversity and distribution of arbuscular mycorrhizal fungi. Soil Biology and Biochemistry, 43, 2294-2303.

Legendre P, Gallagher ED (2001) Ecologically meaningful transformations for ordination of species data. Oecologia, 129, 271-280.

Legendre P, Legendre L (1998) Numerical Ecology, 2nd English edn, pp. 853. Elsevier, New York, NY.

Leibold MA, Holyoak M, Mouquet N et al. (2004) The metacommunity concept: a framework for multi-scale community ecology. Ecology Letters, 7, 601-613.

Langenheder S, Székely AJ (2011) Species sorting and neutral processes are both important during the initial assembly of bacterial communities. ISME Journal, 5, 1086-1094.

Lekberg Y, Koide RT, Rohr JR, Aldrich-Wolfe L, Morton JB (2007) Role of niche restrictions and dispersal in the composition of arbuscular mycorrhizal fungal communities. Journal of Ecology, 95, 95-105.

Liu WT, Marsh TL, Cheng H, Forney LJ (1997) Characterization of microbial diversity by determining terminal restriction fragment length polymorphisms of genes encoding 16SrRNA. Applied and Environmental Microbiology, 63, 4516-4522.
Liu X, Zhang X, Zhang M (2008) Major factors influencing the efficacy of vegetated buffers on sediment trapping: a review and analysis. Journal of Environmental Quality, 37, 1667-1674.

Long L, Carey VJ, Gentleman R (2011) RBGL: R interface to boost graph library. Available at: http://www.bioconductor. org/packages/release/bioc/html/RBGL.html (accessed 30 March 2011).

Mantel N (1967) The detection of disease clustering and generalized regression approach. Cancer Research, 27, 209-220.

Martin KJ, Rygiewicz PT (2005) Fungal-specific PCR primers developed for analysis of the ITS region of environmental DNA extracts. BMC Microbiology, 5, 1-11.

Martiny JBH, Bohannan BJM, Brown JH et al. (2006) Microbial biogeography: putting microorganisms on the map. Nature Reviews Microbiology, 4, 102-112.

May RM (1976) Theoretical Ecology: Principles and Applications, pp. 272. Saunders, Philadelphia, PA.

Moorhead D, Sinsabaugh R (2006) A theoretical model of litter decay and microbial interaction. Ecological Monographs, 76, 151-174.

Nekola JC, White PS (1999) The distance decay of similarity in biogeography and ecology. Journal of Biogeography, 26, 867-878.

Nemergut DR, Costello EK, Hamady M et al. (2011) Global patterns in the biogeography of bacterial taxa. Environmental Microbiology, 13, 135-144.

Oksanen J (2005) Vegan: R functions for vegetation ecologists. Available at: http://cc.oulu.fi/_jarioksa/softhelp/vegan.html (accessed 16 August 2010).

Öpik M, Metsis M, Daniell TJ, Zobel M, Moora M (2009) Large-scale parallel 454 sequencing reveals host ecological group specificity of arbuscular mycorrhizal fungi in a boreonemoral forest. New Phytologist, 184, 424-437.

Or D, Smets BF, Wraith JM, Dechesne A, Friedman SP (2007) Physical constraints affecting microbial habitats and activity in unsaturated porous media - a review. Advances in Water Resources, 30, 1505-1527.

Pajor R, Falconer RE, Hapca SM, Otten W (2010) Modelling and quantifying the effect of heterogeneity in soil physical conditions on fungal growth. Biogeosciences, 7, 3731-3740.

Peay KG, Kennedy PG, Bruns TD (2008) Fungal community ecology: a hybrid beast with a molecular master. BioScience, 58, 799-810.

Peay KG, Garbolotto M, Bruns TD (2010) Evidence of dispersal limitation in soil microorganisms: isolation reduces species richness on mycorrhizal tree islands. Ecology, 91, 3631-3640.

Peres-Neto PR, Jackson DA (2001) How well do multivariate datasets match? The advantages of a Procrustean superimposition approach over the Mantel test. Oecologia, 129, 169-178.

Peres-Neto P, Legendre P, Dray S, Borcard D (2006) Variation partitioning of species data matrices: estimation and comparison of fractions. Ecology, 87, 2614-2625.

Przybyl K, Karolewski P, Oleksyn J, Labedzki A, Reich PB (2008) Fungal diversity of Norway spruce litter: effects of site conditions and premature leaf fall caused by bark beetle outbreak. Microbial Ecology, 56, 332-340.

Rinklebe J, Langer U (2006) Microbial diversity in three floodplain soils at Elbe River (Germany). Soil Biology and Biochemistry, 38, 2144-2151. 
Robinson CH, Szaro TM, Izzo AD, Anderson IC, Parkin PI, Bruns TD (2009) Spatial distribution of fungal communities in a coastal grassland soil. Soil Biology and Biochemistry, 41, 414-416.

Smith VC, Bradford MA (2003) Litter quality impacts on grassland litter decomposition are differently dependent on soil fauna across time. Applied Soil Ecology, 24, 197-203.

Stockmarr A, Andreasen V, stergård H (2007) Dispersal distances for airborne spores based on deposition rates and stochastic modeling. Phytopathology, 97, 1325-1330.

Theuerl S, Buscot F (2006) Laccases: toward disentangling their diversity and functions in relation to soil organic matter cycling. Biology and Fertility of Soils, 46, 215-225.

Tiunov AV, Scheu S (2005) Facilitative interactions rather than resource partitioning drive diversity-functioning relationships in laboratory fungal communities. Ecology Letters, 8, 618-625.

Townsend DE, Fuhlendorf SD (2010) Evaluating relationships between spatial heterogeneity and the biotic and abiotic environments. American Midland Naturalist, 163, 351-365.

Trail F (2007) Fungal cannons: explosive spore discharge in the Ascomycota. FEMS Microbiology Letters, 276, 12-18.

Whittaker RH (1972) Evolution and measurement of species diversity. Taxon, 21, 213-251.

$\mathrm{Wu}$ L, Feinstein LM, Valverde-Barrantes O, Kershner M, Leff L, Blackwood CB (2011) Placing the effects of leaf litter diversity on saprotrophic microorganisms in the context of leaf type and habitat. Microbial Ecology, 61, 399-409.
Wiens JA (1997) The emerging role of patchiness in conservation biology. In: The Ecological Basis for Conservation: Heterogeneity, Ecosystems, and Biodiversity (eds Pickett STA, Ostfeld RS, Shachak M \& Likens GE), pp. 93-107. Springer, New York, NY.

Young IM, Crawford JW (2004) Interactions and self-organization in the soil-microbe complex. Science, 304, 1634-1637.

Zak JC, Visser S (1996) An appraisal of soil fungal biodiversity: the crossroads between taxonomic and functional biodiversity. Biodiversity \& Conservation, 5, 169-183.

Zinger L, Lejon DPH, Baptist F et al. (2011) Contrasting diversity patterns of crenarchaeal, bacterial, and fungal soil communities in an alpine landscape. PLOS ONE, 6 e19950.

L.M.F. and C.B.B. are community ecologists who examine the distributions of microorganisms and plants and their effects on ecosystem processes in soil.

\section{Data accessibility}

TRFLP profiles, leaf identities, proximity matrices, $\mathrm{R}$ code: DRYAD entry doi: 10.5061/dryad.3tm02. 